Journal of

Anesthesia and Surgical Care

\title{
Improvised Anesthetic Management of a Large Pedunculate Mobile Growth at the Base of Tongue: A Unique Scenario
}

\author{
Anuj Jain ${ }^{*}$ \\ Assistant Professor, Department of Anesthesiology, All India Institute of Medical Sciences, Bhopal \\ ${ }^{\star}$ Corresponding author: Anuj Jain, Assistant Professor, Department of Anesthesiology, All India Institute of Medical Sciences, \\ Bhopal; E-mail: anuj.anesth@aiimsbhopal.edu.in
}

Received Date: July 18, 2019 Accepted Date: August 28, 2019 Published Date: August 30, 2019

Citation: Anuj Jain (2019) Improvised Anesthetic Management of a Large Pedunculate Mobile Growth At The Base Of Tongue: A Unique Scenario. J Anesth Surg Care 1: 1-3.

\section{Introduction}

An anticipated difficult airway may be due to difficult bag mask ventilation (BMV) or a difficult direct laryngoscopy (DL). In most of the situations BMV can be achieved which assures oxygenation and check laryngoscopy can be done thereafter. In literature, we talk of absolute contraindications but seldom do we talk of absolute indications. In situations of cannot ventilate and cannot intubate (CVCI), surgical airway is the only option left which has its own complications leading to patient morbidity and mortality. The case discussed here is unique because it involves an unusual cause of difficult BMV, contraindication to DL and an unusual but absolute indication for awake nasal FOB intubation.

\section{Case report}

A 20 years old female presented with a one month history of dysphagia and dyspnea in supine position. Oral examination revealed a jelly like multilobulated mass filling the oropharynx and posterior portion of the oral cavity. Tongue protrusion increased visibility of mass suggesting its attachment to the base of the tongue (BOT).

Indirect laryngoscopy by Otorhinolaryngologist was unsuccessful as the movement of mass with respiration obscured view of the glottis. Diagnostic nasal endoscopy revealed a multilobulated polypoidal mass originating from the BOT. Glottis was visible only at the time of expiration (the expired air pushed the mass away from glottis while inspiration pulled it onto the glottis). Tongue protrusion made visualization of the glottis possible by pulling the mass away from the laryngo-pharynx into the oral cavity.

(C)2019 The Authors. Published by the JScholar under the terms of the Creative Commons Attribution License http://creativecommons.org/licenses/ by/3.0/, which permits unrestricted use, provided the original author and source are credited.
After informed consent of anaesthetic plan and possibility of emergency tracheostomy, standard anesthesia monitors were applied. Patient was nebulized with lignocaine $4 \%$ and premedicated with injection Glycopyrrolate $5 \mathrm{mcg} / \mathrm{kg}$ in the preoperative area. Nasal mucosa decongestion was done using naphazoline nasal spray. Glossopharyngeal, superior laryngeal and recurrent laryngeal nerve blocks were given.

Nasal FOB was done with an adult scope $(5.5 \mathrm{~mm})$ with a $6.5 \mathrm{~mm}$ armoured flexometallic endotracheal tube (ETT) loaded on it. Patient was asked to protrude the tongue in order to remove the mass from the path of vision. Progression of the FOB was done with each expiration (as expired air displaced the mass away from the glottis thereby providing a clearer path for the scope). After visualization of the glottis, FOB was inserted through the glottis into the trachea upto the carina and ETT was rail roaded over it. During the process of railroading, the patient was again requested to protrude tongue in order to prevent trauma or dislodgement of the mass and obstruction of trachea. After tracheal intubation, ETT was secured in place anesthetic induction was done with intravenous propofol $2 \mathrm{mg} /$ $\mathrm{kg}$, fentanyl $2 \mathrm{microgram} / \mathrm{kg}$ and atracurium $0.5 \mathrm{mg} / \mathrm{kg}$. Anes- 
thesia was maintained with Sevoflurane (2\%) in Oxygen : N2O mixture with $\mathrm{FiO} 20.4$.

During surgery, excisional biopsy of the polypoidal mass was done and hemostasis was achieved. Surgical duration was 45 minutes. Absence of oropharyngeal edema was confirmed by DL, after reversal of neuromuscular blockade, trachea was extubated uneventfully.

\section{Discussion}

We present airway management in a patient with anticipated difficult BMV and DL, after administering airway blocks and avoiding sedation to ensure complete patient cooperation. Though oral, oropharyngeal, supraglottic and subglottic masses complicating airway management are reported, our case is unique because the mass was pedunculated with a long stem originating from BOT and causing a ball valve effect on the glottis aperture during respiration. As the mass was likely to obstruct the glottic inlet on inspiration on positive pressure ventilation, difficult BMV was anticipated. Secondly, the fragile mass with its origin from tongue base made DL difficult. Thirdly, with the movement of mass away from glottis only during spontaneous forceful exhalation, maintainence of spontaneous respiration was a must. Last but not the least, patient cooperation was essential to follow verbal command of tongue protrusion during FOB as well as intubation as this moved the mass away from the glottic aperture. In this way, we avoided an imminent emergency tracheostomy and its related complications in a young patient.

Different techniques have been tried in supraglottic masses for intubation. Batra et al. recommended awake FOB nasotracheal intubation for schwannomas [1], lingual thyroid [2] originating from BOT. However, in the scenario described by them, the mass was sessile, solid and did not move with respiration and neither did it obstruct the glottis.

Subglottic masses moving out of glottis aperture on expiration have been described in literature. Pandey et al. successfully did a FOB guided awake intubation in a case of pedunculated subglottic polyp that measured $0.7 \mathrm{~cm}$ by $0.5 \mathrm{~cm}$ with a pedicle of $1.5 \mathrm{~cm}$. Polyp moved above the glottis and stayed there when the patient was asked to take long and deep breaths and hold breath in expiration [3]. (1) In our case, the growth was bigger $(4 \mathrm{~cm}$ by $2 \mathrm{~cm}$ ) and force of expiration required to keep that mass off the glottis was more. The duration for which such power can be maintained is inversely proportional to the size of the growth. Under normal circumstance, forceful expiration can be supported up to $4-5$ seconds, but in our case, this duration was reduced to about 1 seconds, which was insufficient for negotiating the FOB through the glottis. Administration of any amount of sedative would have further complicated this situation. Vadodaria et al successfully managed another case of subglottic polyp with the help of DL and insertion of a $3 \mathrm{~mm}$ Hunsaker tube with a Sanders jet, which was not applicable in our case [4].

Agarwal et al. reported the use of paraglossal straight blade technique for visualization of glottis in cases of vallecular cyst, laryngeal cyst [5]. Paraglossal straight blade could have been used in this case but it could have endangered the rupture of the polyp, besides paraglossal laryngoscopy would have required a deep plane of anesthesia with muscle relaxation which was not safe in this case.

We recommend that anesthetists should be competent in administering airway blocks and technique of awake FOB intubation without supplementation of conscious sedation. In case of such a pedunculated mass originating from BOT, tongue protrusion may be utilized for successful FOB and ETT insertion. These aspects of airway difficulty are unusual and may be a useful addition to the literature on difficult airway management. 


\section{References}

1) Batra UB, Usha G, Gogia AR (2011) Anesthetic management of schwannoma of the base of the tongue. J Anaesthesiol Clin Pharmacol. 27 : 241-243.

2) Jain A, Singh S, Rastogi A (2013) Hyperthyroidism due to hyperfuctioning lingual thyroid presenting for emergency laparotomy. J Anaesthesiol Clin Pharmacol. 29:132-4.

3) R Pandey, R Garg, A Kumar,V Darlong, J Punj, SA Singh (2009) Case report:Airway management of a patient with a popping pedunculated subglottic laryngeal polyp. Acta Anaesthesiologica Belgica. 60:251-253.

4) Vadodaria B, Cooper C.M.S (2001)the anesthetic management of a case of severe upper airway obstruction to enlarging subglottic benign polyp. European Journal of Anesthesiology. 18:766-769.

5) Agarwal S, Asthana V, Meher R, Singh D.K. (2008) Paraglossal straight blade intubation technique-an old technique revisted in difficult intubations:A series of 5 cases.Indian journal of Anesthesia 52:317-320.

Submit your manuscript to a JScholar journal and benefit from:

- Convenient online submission

I Rigorous peer review

- Immediate publication on acceptance

- Open access: articles freely available online

q High visibility within the field

- Better discount for your subsequent articles

Submit your manuscript at http://www.jscholaronline.org/submit-manuscript.php 